\title{
$\beta$-caryophyllene enhances the transcriptional upregulation of cholesterol biosynthesis in breast cancer cells
}

\author{
Mam Y. Mboge ${ }^{1}$, Andrea Ramirez-Mata ${ }^{1}$, Adam Bullock ${ }^{1}$, Riley O'Donnell ${ }^{1}$, John V. Mathias ${ }^{1}$, \\ Julie Davila ${ }^{1}$, Christopher J. Frost ${ }^{2, *, \#}$ and Susan C. Frost ${ }^{1, *, \$}$ \\ ${ }^{1}$ Department of Biochemistry and Molecular Biology, University of Florida, Gainesville, FL, USA; \\ ${ }^{2}$ Department of Biology, University of Louisville, Louisville, KY, USA.
}

\begin{abstract}
$\beta$-caryophyllene (BCP) exhibits anti-proliferative properties in cancer cells. Here, we examine the hypothesis that BCP induces membrane remodeling. Our data show that high concentrations of BCP increase membrane permeability of human breast cells $(\mathrm{hBrC})$ causing detachment and cell death. At a sub-lethal concentration of BCP, we show that $\mathrm{BCP}$ induces a striking upregulation of genes involved in cholesterol biosynthesis, including the gene that encodes for HMGCoA reductase (HMGCR), the rate-determining step in cholesterol biosynthesis. In addition, stearoyl-CoA desaturase (SCD) is also upregulated which would lead to the enhanced formation of monounsaturated fatty acids, specifically oleate and palmitoleate from stearoyl CoA and palmitoyl CoA, respectively. These fatty acids are major components of membrane phospholipids and cholesterol esters. Together, these data suggest that cells respond to BCP by increasing the synthesis of components found in membranes. These responses could be viewed as a repair mechanism and/or as a mechanism to mount resistance to the cytotoxic effect of BCP. Blocking HMGCR activity enhances the cytotoxicity of BCP,
\end{abstract}

\footnotetext{
*Corresponding authors

\#jasmonate@gmail.com

\$sfrost@ufl.edu

The work was performed at the University of Florida, Gainesville, FL and the University of Louisville, Louisville, KY, USA.
}

suggesting that BCP may provide an additional therapeutic tool in controlling breast cancer cell growth.

KEYWORDS: HMG CoA reductase, statins, cytotoxicity, membranes, lipid rafts, cell signaling, nuclear receptors/SREBP, membrane remodeling.

\begin{abstract}
ABBREVIATIONS
$\mathrm{BCP}, \beta$-caryophyllene; SREBP, sterol response element binding protein; SCAP, SREBP cleavageactivating protein; TNBC, triple-negative beast cancer; SCD, stearoyl-CoA desaturase; $\mathrm{HBrC}$, human breast cancer cells; $\mathrm{LDH}$, lactate dehydrogenase; ER, endoplasmic reticulum; HMGCR, HMG CoA reductase; INSIG, insulin-induced gene; S1P and $\mathrm{S} 2 \mathrm{P}$, site 1 protease and site 2 protease; STARD4, StAR-related lipid transfer domain containing 4; GRP78, glucose-regulated protein 78; PFO, perfringolysin O; HER2, human epidermal growth factor 2 .
\end{abstract}

\section{INTRODUCTION}

World-wide, breast cancer is the most common form of cancer in women [1]. Failure to treat metastatic disease is the leading cause of death [2]. Although substantial progress has been made towards treating cancer, such as surgical resections or adjuvant therapies, highly aggressive cancers remain a challenge. One of the deadliest types of cancers in women is triple-negative breast cancer (TNBC), where expression of the estrogen, 
progesterone, and HER2 receptors is either low or absent [3]. This type of cancer is one of the most difficult to treat due to lack of targeted therapies and its inherent therapeutic resistance. TNBC accounts for a disproportionate number of breast cancer deaths [4].

Notable success in the search for novel anti-cancer drugs in natural products has been achieved from the unique chemical reactions associated with plants. Plants create remarkably complex chemicals beyond those that are required for their own growth and reproduction [5]. For generations, these "specialized" metabolites have been used in the treatment of human diseases, even though their active components and molecular targets are not always well-defined [6]. While specialized metabolites are derived from a number of biosynthetic pathways, terpenes are the most abundant class of plant secondary metabolites [7]. In plants, terpenes are synthesized not only through the traditional mevalonate pathway (MVP) which produces the intermediates, isopentenyl pyrophosphate and dimethylallyl pyrophosphate from which terpenes derive, but also via the methylerythritol phosphate pathway [8]. The MVP produces an array of monoterpenes, diterpenes, tetraterpenes, and precursors of complex sterols $[9,10]$. Some plant terpenoids are already well-established for the treatment of breast cancer. For example, paclitaxel (sold under the trade name of Taxol) is an oxygenated diterpenoid that was originally isolated from the Pacific Yew and first shown to stabilize microtubules in the Horwitz lab [11].
As noted by Heinig et al., synthetic paclitaxel is arguably the most successful anticancer drug of all time [12], and is one of the cytotoxic drugs of choice for the treatment of triple-negative and drug-resistant (recurrent) breast cancers [13].

Over the last decade, a number of investigators have demonstrated that $\beta$-caryophyllene (BCP) exhibits anti-proliferative properties in cancer cells $[6,14-19]$. BCP is a bicyclic sesquiterpene (Figure 1) and a major plant volatile of many plant essential oils (like cloves, oregano, black pepper, cinnamon, and cannabis). BCP is often found with small quantities of isocaryophyllene, the oxide form of caryophyllene, and humulene. It was the first known "dietary cannabinoid" and has achieved GRAS (Generally Recognized as Safe) status. Because of its unique taste and pleasant odor, BCP has been used in cosmetics and as a flavoring since the mid 1900's and has FDA approval. It also has well-known antipathogenic properties in plants [20], as well as anti-inflammatory [17, 21], anti-nociceptive [22], and anti-mutagenic [23] properties in animals. Over a decade ago, Legault and Pichette demonstrated that BCP stimulates the accumulation of paclitaxel in DLD-1 (colon cancer) cells, implicating enhanced membrane permeability as a mechanism of action [19]. Indeed, BCP has been shown to interact directly with phospholipid bilayers increasing membrane fluidity [24]. Earlier studies in E. coli showed that cyclic hydrocarbons, including terpenes, interact directly with biological membranes [25]. Accumulation of these hydrocarbons results not only

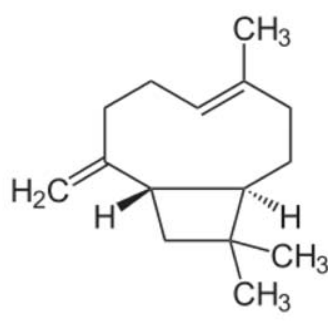

$\mathrm{BCP}$<smiles>CC1=CCC(C)=CCC(C)(C)C=CC1</smiles>

$\alpha$-Humulene

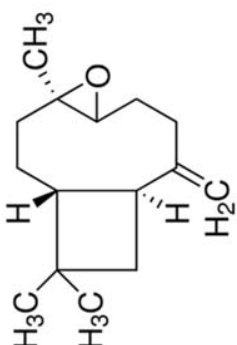

Caryophyllene oxide

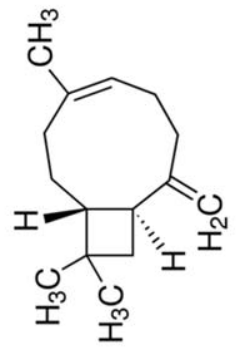

Isocaryophyllene

Figure 1. Isomeric structures of caryophyllene. $\beta$-caryophyllene (BCP) accounts for $\sim 98-99 \%$ found in nature. Other forms of caryophyllene are also shown in this figure that exist with BCP but are less abundant. This figure was adapted from Gertsch et al. [16]. 
in increased membrane fluidity, but also in membrane swelling, both signs of cell stress. At biological temperatures, membrane fluidity is controlled by the saturation state of the acyl chains of fatty acids (primarily in phospholipids) and cholesterol content [26]. Changes in either of these parameters could lead to membrane remodeling which can affect membrane function.

Here, we examine the hypothesis that BCP induces membrane remodeling. Our data show that high concentrations of BCP increase membrane permeability of human breast cells $(\mathrm{hBrC})$ causing detachment and cell death. At a "sub-lethal" concentration of BCP, we show that BCP induces a striking upregulation of genes involved in cholesterol biosynthesis, including the gene that encodes for HMGCoA reductase (HMGCR), the rate-determining step in cholesterol biosynthesis. Many of the identified genes are regulated by the transcription factor SREBP-2 whose activation is regulated by cholesterol availability (for review see [27]). In addition, stearoyl-CoA desaturase (SCD1) is also upregulated. This endoplasmic reticulum (ER) enzyme catalyzes the rate-limiting step in the formation of monounsaturated fatty acids, specifically oleate and palmitoleate from stearoyl CoA and palmitoyl CoA, respectively. These fatty acids are major components of membrane phospholipids, cholesterol esters, and alkyl-diacyglycerol. Together, these data suggest that cells respond to sub lethal concentrations of BCP by increasing the synthesis of components found in membranes. These responses could be viewed both as a repair mechanism and potentially as a mechanism to mount resistance to the cytotoxic effect of BCP. We show that blocking the repair mechanism using simvastatin enhances the cytotoxicity of BCP. Thus BCP may offer an addition therapeutic tool in controlling breast cancer cell growth.

\section{MATERIALS AND METHODS}

\section{Cell culture}

All cell lines were authenticated. MCF10A cells were a gift from Dr. Brian Law. Dr. Keith Robertson provided T47D cells. The MDA-MB231-LM2 cells were a gift from Dr. Dietmar Siemann and the UFH-001 line was developed in the lab of SC Frost [28], both of which have the triple-negative phenotype. Each line was maintained at $37^{\circ} \mathrm{C}$ at $5 \% \mathrm{CO}_{2}$. MCF $10 \mathrm{~A}$ cells were cultivated in Dulbecco's Modified Eagle's Medium (DMEM/ Ham's F12 medium (1:1) (Corning Lellgro) supplemented with 5\% horse serum (Sigma Aldrich), $10 \mu \mathrm{g} / \mathrm{ml}$ insulin (Eli Lilly), $20 \mathrm{ng} / \mathrm{mL}$ epidermal growth factor (EGF) (Upstate Biochem) and $100 \mathrm{ng} / \mathrm{mL}$ dexamethasone (Sigma Aldrich). The T47D cells were maintained in McCoy's medium (Gibco) containing 10\% fetal bovine serum (FBS; Sigma Aldrich) and $1 \mu \mathrm{g} / \mathrm{mL}$ bovine insulin (Elanco). The MDA-MB-231-LM2 and UFH-001 cell lines were cultivated in DMEM supplemented with $10 \%$ FBS.

\section{Viability assays}

To measure the viability of cells exposed to $\beta$-caryophyllene (Sigma/Aldrich \# 22075), we measured mitochondrial function using thiazolyl blue (MTT) from Sigma/Aldrich (\# M5655). Briefly, cells were seeded in 96 well plates and treated with increasing concentration of drugs. The cells were incubated with BCP for $4 \mathrm{~h}, 8 \mathrm{~h}$, and $24 \mathrm{~h}$ under normoxic conditions. In some experiments, we tested the effect of paclitaxel for a duration of $24 \mathrm{~h}$ or $48 \mathrm{~h}$. Thiazolyl blue was added $4 \mathrm{~h}$ before the end of each time point. The medium was then removed without disrupting the cells and DMSO was added for 15 min to each well. Absorbance was read at $570 \mathrm{~nm}$ using an Epoch microplate reader (Biotek). Data represent the average \pm SEM of three biological replicates.

\section{Cytotoxicity assays}

To measure the cytotoxic effects of BCP and paclitaxel, we used the release of lactate dehydrogenase (LDH), measured as the production of NAD (Sigma/Aldrich, \# MA0K066). Cells were grown in $35 \mathrm{~mm}$ dishes and exposed to specific concentrations of $\mathrm{BCP}$ at times indicated in the figure legends. In some experiments, we tested the effect of paclitaxel over $48 \mathrm{~h}$. At high concentrations of BCP, but not of paclitaxel, it was noted that cells were released from the plate. Medium was separated from cells by centrifugation $(13,200 \mathrm{xg}$ for $5 \mathrm{~min})$ before sampling the medium for LDH activity. Absorbance was read at $450 \mathrm{~nm}$ using the Epoch microplate reader. LDH activity is reported as nmoles $/ \mathrm{min} / 10^{6}$ cells, based on 
cell counts at the start of each experiment. Data represent the mean \pm SEM from three 3 biological replicates.

\section{RNA isolation and RNAseq}

To measure the effect of $\mathrm{BCP}$ on global gene expression, we used RNAseq technology. RNA $(\mathrm{RIN}>9)$ was extracted from UFH-001 cells, previously exposed to normoxia or hypoxia for $16 \mathrm{~h}$ in the presence or absence of BCP at either $20 \mu \mathrm{M}$ or $200 \mu \mathrm{M}$ (RNase easy plus mini kit from Qiagen). Libraries were prepared at the Genomics Core at the University of Louisville and sequencing was performed on triplicate biological replicates (Illunima NestSeq 500). This generated over 144 million $75 \mathrm{bp}$ reads that aligned to the human genome (96.3\% alignment rate), or approximately 24 million reads per sample. The data discussed in this publication have been deposited in NCBI's Gene Expression Omnibus [29] and are accessible through GEO Series accession number GSE125511 (https://www.ncbi.nih.gov/geo/query/acc.cgi?acc= GSE125511).

\section{Membrane preparation}

Cells were washed 3 times with ice cold phosphate-buffered saline (PBS, pH, 7.4). Cells were then homogenized in buffer containing $20 \mathrm{mM}$ Tris base, $1 \mathrm{mM}$ EDTA, and $255 \mathrm{mM}$ sucrose, $\mathrm{pH}$ 7.4, supplemented with $1 \mathrm{mM}$ phenylmethyl sulfonyl fluoride (PMSF) and protease inhibitor cocktail (Sigma/Aldrich, P-8340). Membranes were collected by centrifugation at $212,000 \mathrm{x} \mathrm{g}$ for $60 \mathrm{~min}$ at $4^{\circ} \mathrm{C}$. Membranes were resuspended in a small volume of the same buffer and stored at $-20^{\circ} \mathrm{C}$.

\section{Lysate preparation}

Cells were washed 3 times with ice cold PBS and then extracted in RIPA buffer [1\% Triton X-100, $10 \mathrm{mM}$ Tris- $\mathrm{HCl}$ (pH 8.0), $140 \mathrm{mM} \mathrm{NaCl}, 1 \mathrm{mM}$ EDTA, 0.5 mM EGTA, 0.1\% sodium deoxycholate, $0.1 \%$ SDS] supplemented with PMSF and protease inhibitor cocktail for $15 \mathrm{~min}$ on ice. Lysates were clarified by centrifugation at 212,000 x g for $60 \mathrm{~min}$ at $4{ }^{\circ} \mathrm{C}$. Clarified supernatants were collected and stored at $-20{ }^{\circ} \mathrm{C}$. Protein concentrations for both membranes and cell lysates were determined using the Markwell modification of the Lowry procedure [30].

\section{SDS-PAGE and western blotting}

One-dimensional SDS-polyacrylamide gel electrophoresis (SDS-PAGE) was performed essentially as described by Laemmli et al. [31]. Protein samples were mixed with sample dilution buffer. Gels $(10 \%)$ were typically run overnight at room temperature at approximately $45 \mathrm{~V}$ in a Hoefer SE 600 electrophoresis unit. Protein samples were electro-transferred from SDS-PAGE gels to nitrocellulose membranes in transfer buffer (25 mM Tris-base, $192 \mathrm{mM}$ glycine, $20 \%$ methanol) at $200 \mathrm{~mA}$ for $2 \mathrm{~h}$ at $4{ }^{\circ} \mathrm{C}$. Western blotting was accomplished as previously described [32]. Enhanced chemiluminescence (ECL) was used according to manufacturer's directions (GE Healthcare, \#RPN2106 or RPN2232). Santa Cruz antibodies were used for analysis of HMGCR (sc-271595) and $\mathrm{Na}^{+} \mathrm{K}^{+}$ ATPase (sc-28800). The GAPDH antibody was from Cell Signaling (D16H11). Band intensity was quantified using Un-Scan-It (Silk Scientific, Inc.) in the linear range of the film.

\section{Cholesterol quantification}

Cholesterol concentration was estimated using a kit from Sigma/Aldrich (MAK043). Briefly, cells (in $35 \mathrm{~mm}$ plates) were washed with PBS, and collected by centrifugation in $0.5 \mathrm{~mL}$ PBS. After removing the buffer, cholesterol was extracted with $200 \mu \mathrm{L}$ of chloroform/isopropanol/IGEPAL (ratio of 7:11:0.1) according to instructions by the manufacturer. This was mixed vigorously and then exposed to centrifugal force $(13,000 \mathrm{x} \mathrm{g})$ in the cold for $10 \mathrm{~min}$. The organic phase was transferred to a new tub and dried at $50{ }^{\circ} \mathrm{C}$. Residual solvent was removed under vacuum (Savant). Dried samples were resuspended in assay buffer, and mixed on a vortex. This was used to measure total cholesterol. We also assessed the effect of BCP on steadystate uptake of $\left[{ }^{3} \mathrm{H}\right]$-cholesterol. Cells were equilibrated for $8 \mathrm{~h}$ in DMEM containing 10\% FBS, and spiked with $1 \mathrm{uCi} / \mathrm{uL}\left[1,2^{3} \mathrm{H}(\mathrm{N})\right]$ cholesterol (NET19001MC, 44.5Ci/mmol). Cells were then exposed to $\mathrm{BCP}$ under normoxic and hypoxic conditions for $16 \mathrm{~h}$. Samples were taken from the medium before washing cells with ice-cold PBS. Cells were extracted in $1.0 \mathrm{~mL}$ of $0.1 \%$ sodium dodecyl sulfate. Samples were collected for counting and protein analysis. Data represent the $\operatorname{avg} \pm$ SEM of three biological replicates. 


\section{Statistical evaluation}

Unless otherwise noted, each experiment was repeated three times and reported as the average \pm S.E.M. Statistical analysis was performed using Prism 7 software using the Student's t-test. $p$ values $<0.05$ was considered statistically significant and are reported in the Figure legends.

\section{RESULTS}

\section{Effect of BCP on metabolic function and cytotoxicity in breast cancer cells}

Because it has been reported that BCP enhances growth inhibition in a prostate cell line induced by paclitaxel [19], we analyzed the effect of paclitaxel across a panel of human breast cancer cell lines $(\mathrm{hBrC})$. We first determined the effect of paclitaxel on cell growth (Supplementary Figure 1). This panel represents a control line (MCF10A), an $\mathrm{ER}+$ luminal line (T47D), and two triple-negative lines (MDA-MB-231-LM2 and UFH-001 [33]). The characteristics of the new UFH-001 line have been described elsewhere [28]. We used the MTT assay, which measures mitochondrial function, as a surrogate measure of cell number. At both 24 and $48 \mathrm{~h}$, the MDA-LM2 and UFH-001 lines were more sensitive to growth inhibition by paclitaxel than either the MCF10A or T47D cells (Supplementary Figures 1A and 1B). This was not surprising given that these cells replicate more quickly, in our hands, than the MCF10A or T47D cells. However, we were unable to detect any amplification by $70 \mu \mathrm{M}$ BCP on paclitaxel-induced cell growth (Supplementary Figure 1C). The BCP concentration used here was similar to that used by Legault and Pichette [19]. While paclitaxel induced some cytotoxicity in the UFH-001 line as measured by lactate dehydrogenase (LDH) release from cells, $\mathrm{BCP}$ at $70 \mu \mathrm{M}$ did not further influence cytotoxicity of either the UFH cells or the other cells tested (Supplementary Figure 1D). Reasons for these differences between our data and those previously published could be related to the sensitivity of the breast cancer cell lines relative to the prostate line used previously. That said, we must still conclude from our data that paclitaxel action in the cell lines that we tested is not potentiated by BCP.

Earlier studies reported that $\mathrm{BCP}$ exhibits anticancer activity but that the $\mathrm{EC}_{50}$ values vary with cell type [15]. We repeated these experiments to determine if $\mathrm{BCP}$ is cytotoxic to the four $\mathrm{hBrC}$ lines and to establish dose-response curves. We again measured LDH release, this time over $4 \mathrm{~h}$, in the presence or absence of specific concentrations of BCP. In Figure 2, we show the total LDH activity released during that time frame (Panel A), the activity with the background subtracted (Panel B), and normalized data in percent released (Panel C). In agreement with earlier studies, the sensitivity to $\mathrm{BCP}$ varied 2-3 fold across cell lines (Panel C), although the $\mathrm{EC}_{50}$ values for all $\mathrm{hBrC}$ lines were in high $\mu \mathrm{M}$ concentrations. Concentrations at which we observed elevated LDH activity corresponded to an increase in the number of floating cells. Together, these data demonstrate that BCP interacts with $\mathrm{hBrC}$ cells causing detachment from the extracellular matrix, enhancing membrane permeability, and leading to cell death, not necessarily in that order. It is noteworthy that loss of mitochondrial function in UFH cells (Supplementary Figure 1C) occurs at $200 \mu \mathrm{M}$ while cytotoxicity requires higher concentrations (Figure 2C). This opened an opportunity to investigate mechanisms that might be responsible for BCP action in the absence of cytotoxicity.

\section{Effect of BCP on transcriptional activity in UFH-001 cells}

The UFH-001 line exhibits the TNBC phenotype, is fast growing in culture, and forms tumors in mouse models [28]. Even though these were not the most sensitive to $\mathrm{BCP}$, we chose to analyze UFH-001cells because targeted therapies for TNBC patients are not available. Because hypoxia is the environment associated with aggressive breast cancers, and an independent prognosticator for poor patient outcome [34], we also chose the condition of hypoxia to evaluate the effect of BCP. In addition, we extended the exposure time from $4 \mathrm{~h}$ (Figure 2) to $16 \mathrm{~h}$ (Figure 3 ) to allow for transcriptional responses. We have previously shown that the levels of the hypoxia-inducible transcription factor $1 \alpha$ (HIF1 $\alpha$ ) increase at the protein level in these cells in response to $16 \mathrm{~h}$ exposure to both hypoxia and the hypoxic mimic desferroxamine mesylate [35] confirming their sensitivity to low oxygen conditions. Thus, the cells were exposed to $1 \%$ oxygen (hypoxia) in the presence of $20 \mu \mathrm{M}, 200 \mu \mathrm{M}$ BCP or vehicle alone 
A

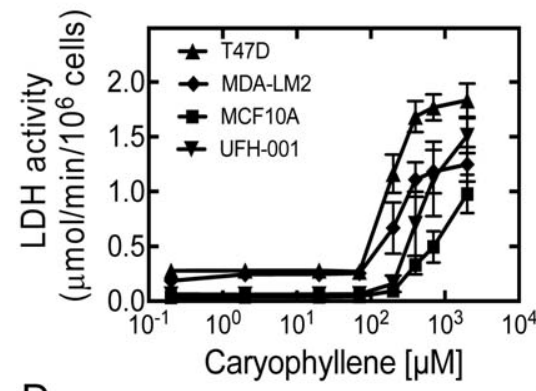

$\mathrm{D}$

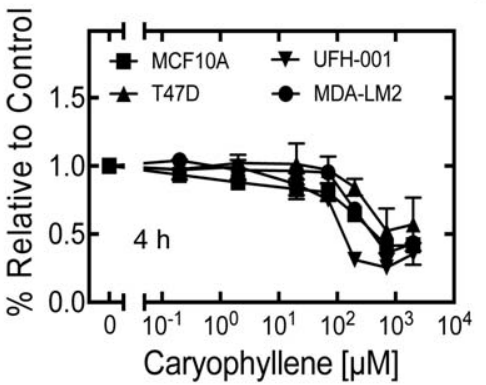

B

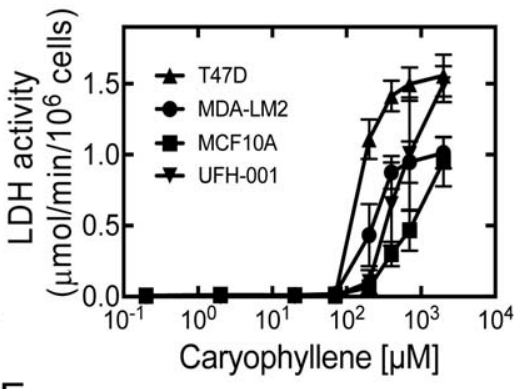

E

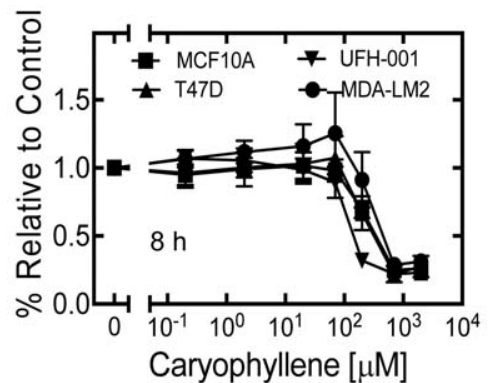

C

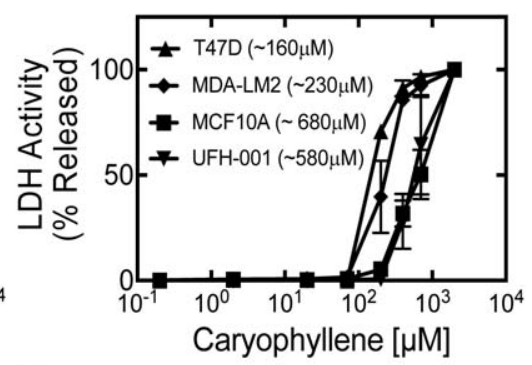

$\mathrm{F}$

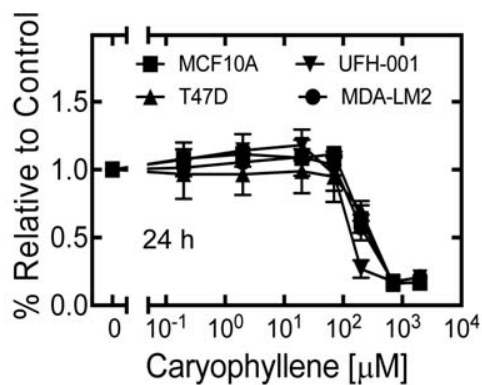

Figure 2. BCP reduces cell viability of breast cancer cells. Cells were treated with increasing concentrations of BCP. LDH release was measured after $4 \mathrm{~h}$ (Panels A-C), showing total activity, background subtracted activity and percent of $\mathrm{LDH}$ release relative to the control for each cell line. Panel $\mathrm{C}$ shows the $\mathrm{IC}_{50}$ values for BCP. MTT assays were performed after 4, 8 and $24 \mathrm{~h}$ (Panels D-F). Data shown represent the average of at least 3 biological replicates \pm S.E.M.

(DMSO) over $16 \mathrm{~h}$ (Figure 3). We note that there is no difference in BCP-induced cytotoxicity between normoxic and hypoxic cells at $16 \mathrm{~h}$ (Supplementary Figure 2).

RNA was isolated from cells to determine changes in the transcriptome of cells exposed to BCP. As a first approach, we selected differentially expressed genes based on FDR-adjusted p-values (q-values) of $<0.05$, and analyzed this gene set for pathway involvement using the Reactome database. Because Reactome also assesses the FDR for pathway analysis, we again selected an FDR $<0.05$ to enhance specificity. Data complied in Table 1 show that lipid metabolism in pathways regulated by the SREBP family of transcription factors are key targets of BCP action. Also of note in Table 1 is the activation of inflammatory processes through interleukin 10 (IL10) signaling and processing of interleukin 1 (IL1) suggesting that the cells are experiencing ROS-mediated stress.

The exceptional specificity of BCP action is illustrated in Figure 3, modeled in part after Horton et al. [36]. The asterisks indicate those genes that are significantly induced by $\mathrm{BCP}$ $(\mathrm{q} \leq 0.05)$. Remarkably, 17 of the 19 genes in cholesterol biosynthesis (including HMGCR, the rate-limiting step in the pathway) are induced by $\mathrm{BCP}$. Interestingly, elevated expression of this gene is associated with poor prognosis in TNBC, but not estrogen receptor-positive breast cancer patients (Figure 4) according to the Kaplan-Meier data base (kmplot.com/analysis) using a web tool developed by Lanczky et al. to query the databases [37]. The coordinated regulation of cholesterol biosynthesis in the UFH-001 cells is reminiscent of those revealed by the early studies of Brown and Goldstein [38]. Moreover, our results suggest that BCP modulates fatty acid saturation, as stearoyl CoA desaturase (SCD1) is also upregulated (Figure 3). SCD1 is a transmembrane, ER-resident protein whose function is to create monosaturated fatty acids, specifically oleate and palmitoleate from stearoyl CoA and palmitoyl CoA, respectively. These are major components of membrane phospholipids, and suggest that BCP-treated cells may respond to membrane damage by enhancing 
$\frac{0}{0}$
0
$\frac{0}{5}$
0
$\frac{0}{0}$
$\frac{0}{0}$
$\frac{0}{0}$
$\frac{0}{0}$
$\frac{1}{0}$

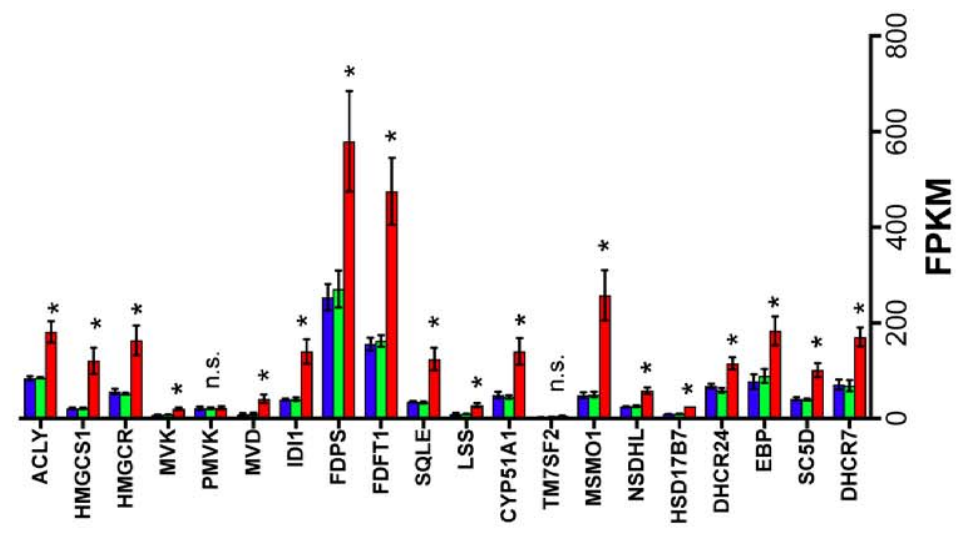

용 $\stackrel{0}{=}$

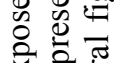

ब.

웡

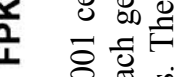

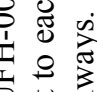

范

谙

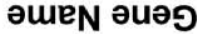

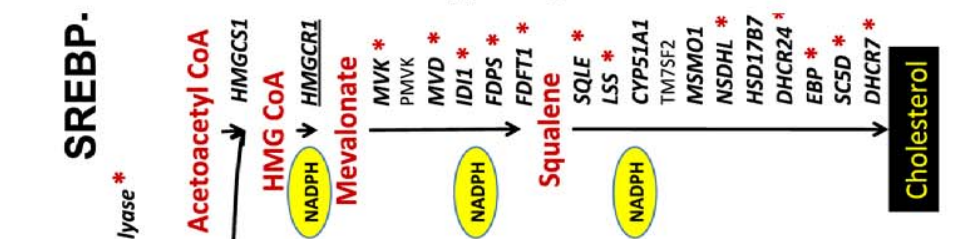

宗: 믐

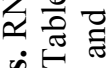

$\dot{\dot{m}}$

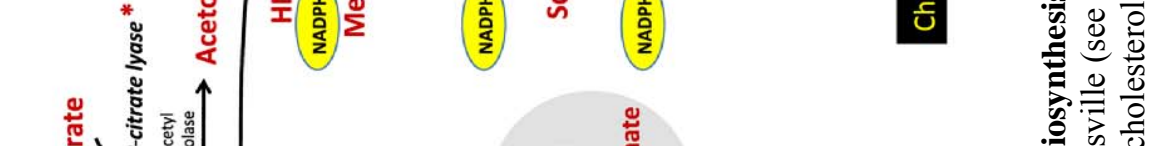
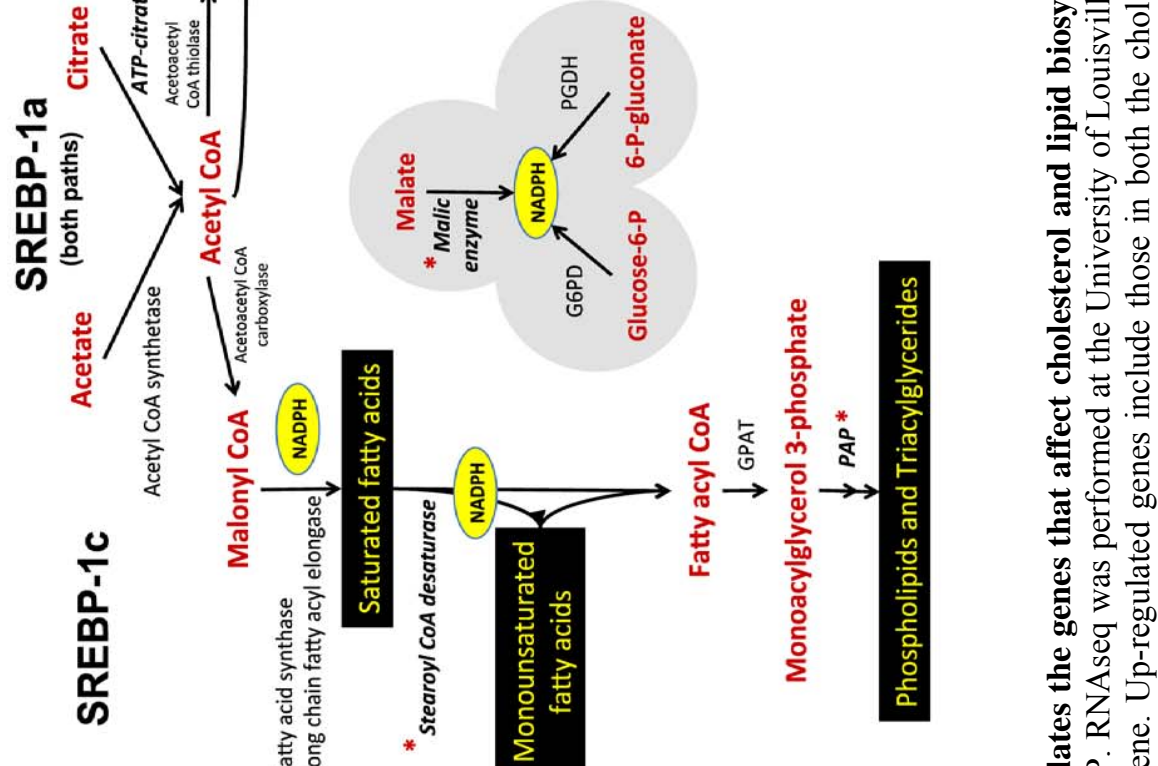

矛需

울.

要

远

边

है

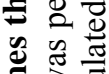

茄 3

至若

兄。

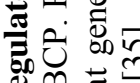

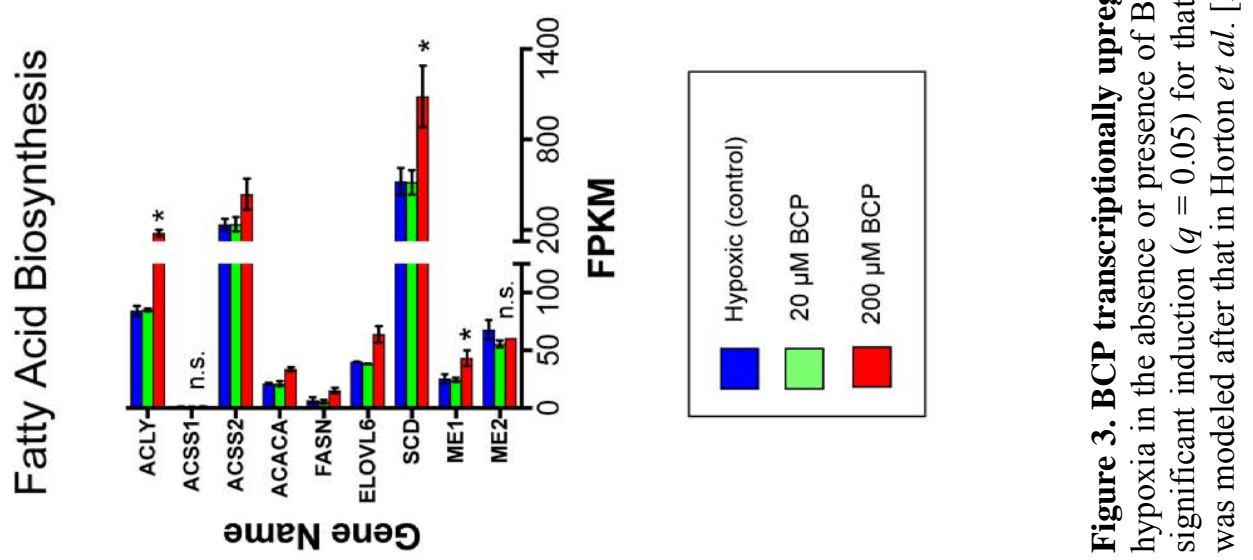


Table 1. Pathways induced by BCP (RNA-seq pilot data using UFH-001 cells). High quality RNA (RIN $>9$ ) was isolated from UFH-001 cells exposed to hypoxia with and without $200 \mu \mathrm{M}$ BCP. The Genomics Core (University of Louisville) prepared libraries and performed sequencing (Illumina NextSeq 500). We selected differentially expressed genes based on FDR-adjusted p-values (q-values) $\leq 0.05$, and analyzed this gene set for pathway involvement using the Reactome database. Because Reactome also assesses the FDR for pathway analysis, we again selected an FDR $<0.05$ to enhance specificity.

\begin{tabular}{|l|l|c|c|c|}
\hline \multicolumn{1}{|c|}{ Pathway identifier } & \multicolumn{1}{|c|}{ Pathway name } & Entities found & p value & FDR \\
\hline R-HSA-191273 & Cholesterol biosynthesis & 18 & $1.11 \mathrm{E}-16$ & $9.21 \mathrm{E}-15$ \\
\hline R-HSA-2426168 & $\begin{array}{l}\text { Activation of gene expression by SREBP } \\
\text { (SREBP) }\end{array}$ & 26 & $1.11 \mathrm{E}-16$ & $9.21 \mathrm{E}-15$ \\
\hline R-HSA-1655829 & $\begin{array}{l}\text { Regulation of cholesterol biosynthesis by } \\
\text { SREBP (SREBF) }\end{array}$ & 27 & $1.11 \mathrm{E}-16$ & $9.21 \mathrm{E}-15$ \\
\hline R-HSA-8957322 & Metabolism of steroids & 34 & $1.11 \mathrm{E}-16$ & $9.21 \mathrm{E}-15$ \\
\hline R-HSA-556833 & Metabolism of lipids & 44 & $2.11 \mathrm{E}-15$ & $1.39 \mathrm{E}-13$ \\
\hline R-HSA-1989781 & PPARA activates gene expression & 14 & $8.06 \mathrm{E}-10$ & $4.43 \mathrm{E}-08$ \\
\hline R-0HSA-400206 & $\begin{array}{l}\text { Regulation of lipid metabolism by } \\
\text { Peroxisome proliferator-activated }\end{array}$ & 14 & $9.97 \mathrm{E}-10$ & $4.69 \mathrm{E}-08$ \\
\hline R-HSA-6783783 & Interleukin-10 signaling & 8 & $1.43 \mathrm{E}-06$ & $5.87 \mathrm{E}-05$ \\
\hline R-HSA-6807047 & Cholesterol biosynthesis via desmosterol & 4 & $8.63 \mathrm{E}-06$ & $2.85 \mathrm{E}-04$ \\
\hline R-HSA-6807062 & Cholesterol biosynthesis via lathosterol & 4 & $8.63 \mathrm{E}-06$ & $2.85 \mathrm{E}-04$ \\
\hline R-HSA-1430728 & Metabolism & 48 & $4.88 \mathrm{E}-04$ & 0.014637 \\
\hline R-HSA-448706 & Interleukin-1 processing & 2 & 0.0018436 & 0.049779 \\
\hline
\end{tabular}

the biosynthetic path for both fatty acids and cholesterol.

\section{BCP increases HMGCR expression and cholesterol content}

Western blot analysis was used to assess the expression of the HMGCR. BCP had no affect on HMGCR expression under normoxic conditions (Figures 5B, C), although expression was higher than under hypoxic conditions. In contrast, HMGCR expression was increased significantly by $200 \mu \mathrm{M}$ relative to vehicle control after exposure to hypoxia (Figures 5B, C), replicating the RNAseq data (Figures 3 and 5A). This correlated with the accumulation of cholesterol (Figure 5D) where only hypoxic treatment in the presence of $200 \mu \mathrm{M}$ achieved significance relative to vehicle control. We also measured the ability of cells to accumulate external $\left[{ }^{3} \mathrm{H}\right]$ cholesterol, assuming that this may represent association within the plasma membrane.
Surprisingly, significant accumulation was detected in the presence of $200 \mu \mathrm{M} \mathrm{BCP}$ under both normoxic and hypoxic conditions (Figure 5E).

\section{Simvastatin increases BCP-induced cytotoxicity}

The action of BCP appears to be concentration dependent. At sub-cytotoxic levels it appears to promote lipid biosynthesis which may be used for membrane biosynthesis while at very high concentrations it induces cytotoxicity (cell death). We reasoned that blocking cholesterol biosynthesis at sub-lethal concentrations of BCP would enhance cytotoxicity. To test this, we first analyzed the effect of two inhibitors (Atorvastatin and Simvastatin) of HMGCR on cell growth of UFH-001, T47D, and MCF10A cells using the MTT assay (Figures 6 A-C). The sensitivity of these drugs varied with cell type: UFH-001 > $\mathrm{T} 47 \mathrm{D}>\mathrm{MCF} 10 \mathrm{~A}$ based on $\mathrm{IC}_{50}$ values. In each 

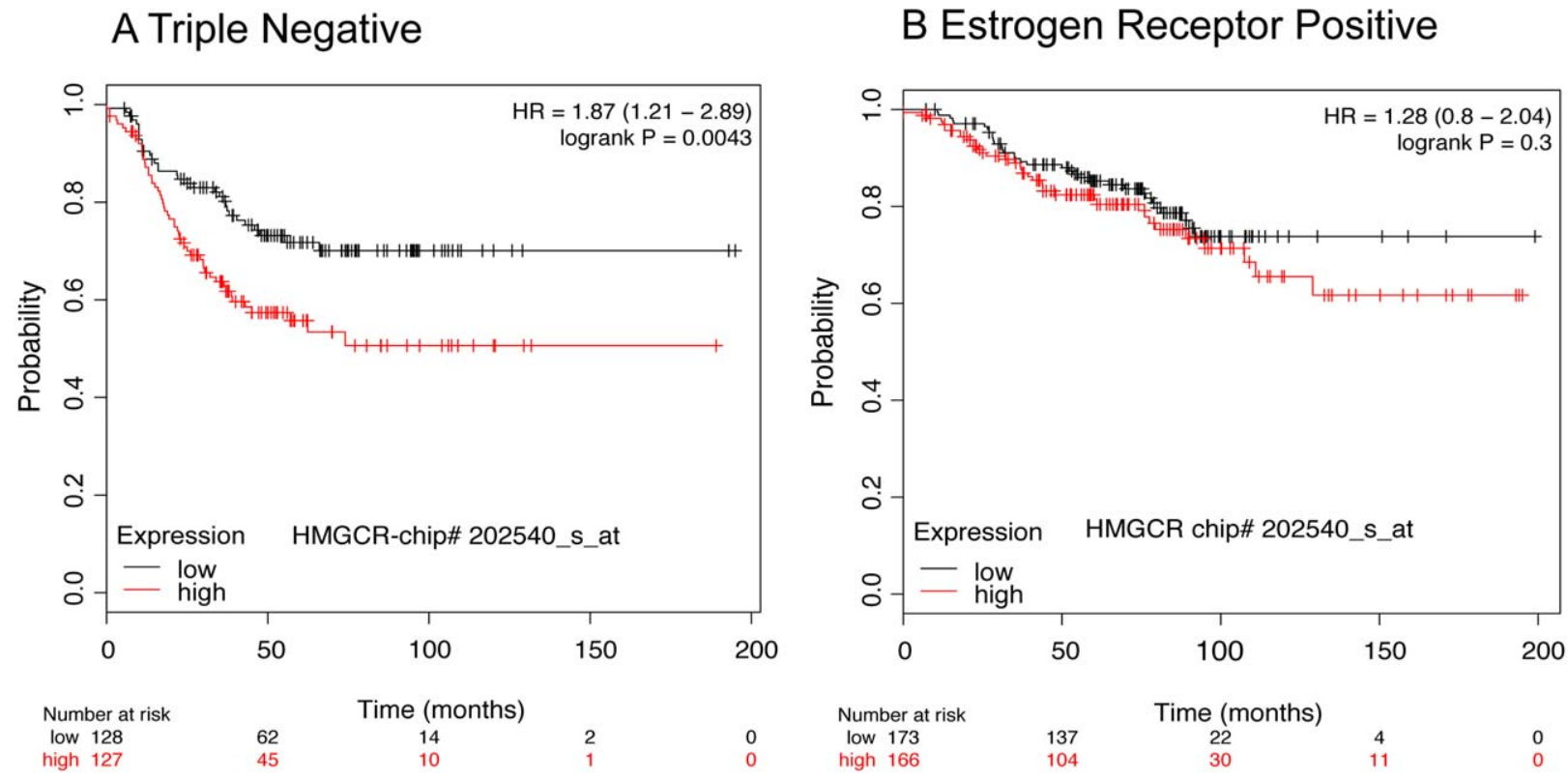

Figure 4. HMGCoA Reductase is a poor prognosticator for triple-negative breast cancer patient survival. Kaplan Meier survival curves are shown in Panels A and B. Panel A represents survival curves (RFS) of TNBC patients with low or high expression of HMGCoA reductase $(p=0.0043)$. Panel B represents survival curves (RFS) of ER-positive patients with low or high expression of HMGCoA reductase (no significance). These data were compiled using a web tool designed by Lanczky et al. [36] to analyze data in the Kaplan Meier database. In each figure, the black line is associated with low HGMCoA reductase activity, while the red line depicts high expression of the reductase.

cell line, simvastatin was a better inhibitor of cell growth than atorvastatin under our conditions. Only simvastatin sensitized UFH-001 cells to the cytotoxic effects of BCP (compare Figure 6E with $6 \mathrm{D}$ ), but this shift was only about 2 fold (Figure 6F).

\section{BCP activates a feed back loop}

Besides the genes that encode for the enzymatic reactions in cholesterol and lipid biosynthesis, we also evaluated the transcription of key regulators of cholesterol homeostasis (Figure 7). SREBP-1 transcripts were elevated relative to SREBP-2, which is more selective over cholesterol biosynthesis. Although it would appear that transcription of SREBP-1 and SREBP-2 are regulated in opposite directions by $\mathrm{BCP}$, neither of these changes achieved a $\mathrm{q}$ value of $\leq 0.05$. When cholesterol levels are low, both SREBP-1 and SREBP-2 are escorted to the Golgi by the cholesterol-sensing protein, SREBP cleavage-activating protein (SCAP). SCAP transcription is not affected by BCP. In the Golgi, the SREBPs encounter two specific proteases,
S1P and S2P. These are responsible for the sequential cleavage of the SREBP's to generate the "mature" transcription factor that then travels to the nucleus. Transcription of neither S1P nor S2P was enhanced by BCP. GP78 and TRC 8 are E3 ubiquitin ligases that modulate the posttranslation polyubiquitination of HMGCR to enhance cholesterol-dependent proteasomal degradation. Neither of these genes were regulated by BCP. SCAP localization depends on cholesterol levels in the ER. Above a certain threshold, SCAP is retained in the ER by the ER-resident proteins, insulin-induced gene 1 or 2 (INSIG1 or INSIG2), which binds to SCAP preventing its chaperone function. The number of transcripts for INSIG2 was higher than that for INSIG1, but INSIG1 was significantly upregulated by BCP $(q=0.013)$. Finally, we measured the expression of STARD4 transcripts. STARD4 is a cholesterol-specific transporter that moves cholesterol between membranes $[39,40]$. BCP significantly stimulated transcription of this member of the START family $(q=0.013)$. These latter data suggest that BCP 
A
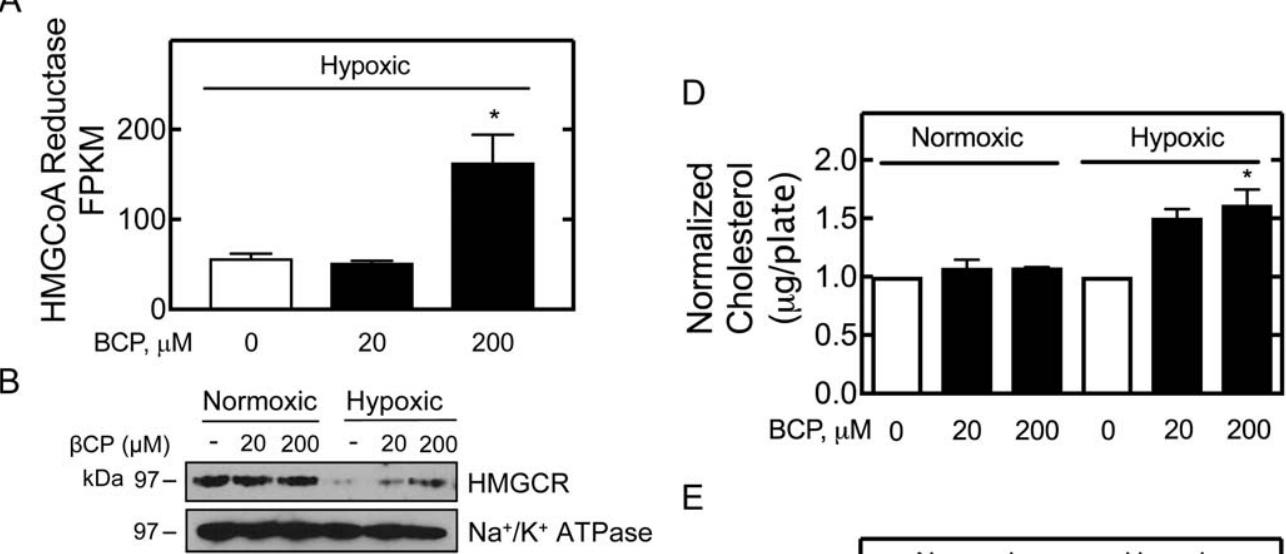

C

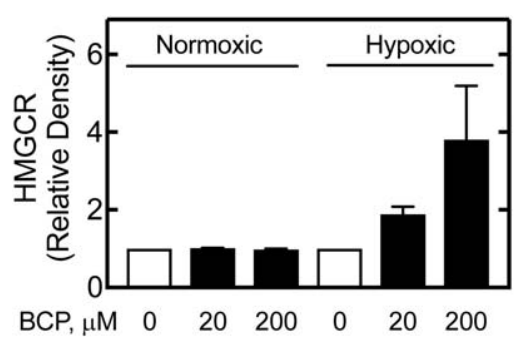

$\mathrm{E}$

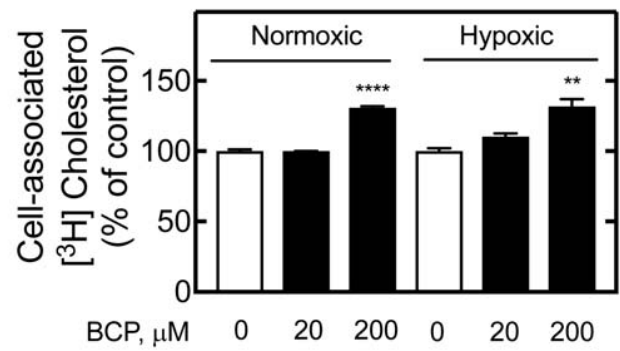

Figure 5. BCP regulates HMGCoA reductase expression in response to BCP in UFH-001 cells. Panel A. FPKM values for HMG CoA reductase, $\mathrm{n}=3 .{ }^{*} \mathrm{q}=0.013$. Panel B. Membranes were isolated from UFH-001 cells exposed or not to hypoxia in the presence or absence of BCP for $24 \mathrm{~h}$. HMGCoA reductase expression was assessed by western blotting. A representative blot is shown. Panel C. Analysis of bands (UN-SCAN-IT vs 5.3) from replicate western blots of HMG CoA reductase are presented as relative density (avg \pm S.E.M.). Panel D. Total cholesterol was quantified after Folch extraction of UFH-001 cells, treated as in Panel A, using the Cholesterol Quantification Kit from Sigma/Aldrich (MAK043). These data represent three biological replicates and are reported as $\mu \mathrm{g} / \mu \mathrm{L}$ extract \pm S.E.M., relative to DMSO controls $(*, p=0.038)$. Panel E. Radioactive cholesterol associated with UFH-001 cells was measured after preloading cells for $8 \mathrm{~h}$ with tracer amounts of $\left[{ }^{3} \mathrm{H}\right]$ cholesterol ( $\sim 480,000 \mathrm{cpm} / \mathrm{mL}$ medium) followed by exposure to normoxia or hypoxia, with or without BCP as in Panel A. Data are reported as percent of normoxic or hypoxic controls, based on $\mathrm{cpm} / \mu \mathrm{g}$ protein, in triplicate samples \pm S.E.M. ${ }^{* *}, \mathrm{p}<0.01 ; * * * *, \mathrm{p}=0.0001$.

not only activates the biosynthetic path, but initiates a negative feedback system, as well, to ultimately turn off the biosynthetic process.

\section{DISCUSSION}

While BCP is cytotoxic to breast cancer cells at high concentrations, we show for the first time that sub lethal concentrations induce the transcription of nearly all of the genes encoding proteins involved in cholesterol biosynthesis, and a significant few involved in fatty acid biosynthesis. This is reminiscent of the response caused by cholesterol depletion, where activation of the transcription factor SREBP2 leads to the global upregulation of genes dedicated to cholesterol biosynthesis [41]. There appears to be a very tight switch between the concentration of $\mathrm{BCP}$ that induces gene transcription and that leading to cytotoxicity. Because terpenes, in general, interact with membranes to induce swelling and changes in fluidity, it is possible that there is some specific level of membrane stress which is sensed by cells allowing them to mount an offense that attempts to replenish lost lipid, thereby maintaining membrane integrity. Indeed, others have shown that plasma membranes (PM) are not only targets of stress, but also sensors in activating stress responses [42]. Any alterations in lipid fluidity within PM lipid microdomains, particularly that of the sphingomyelin and cholesterol-rich environment 
A

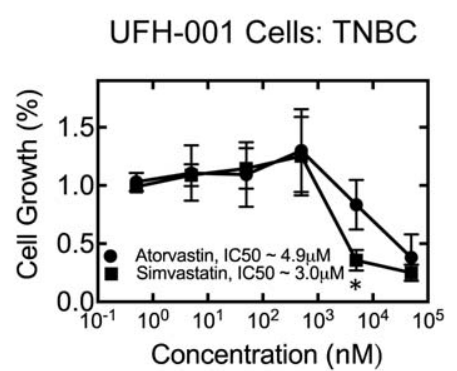

$\mathrm{D}$

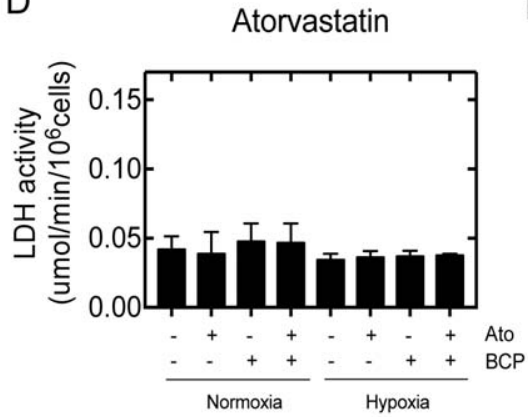

B

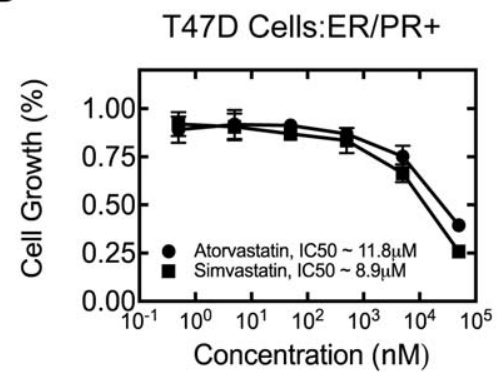

E

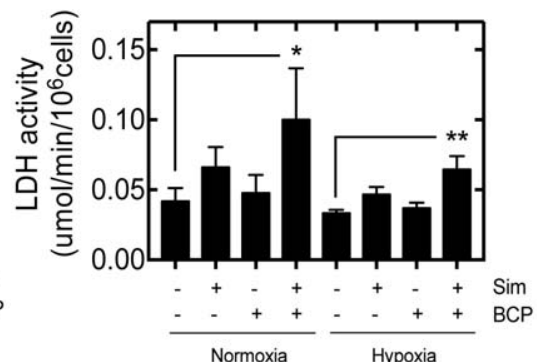

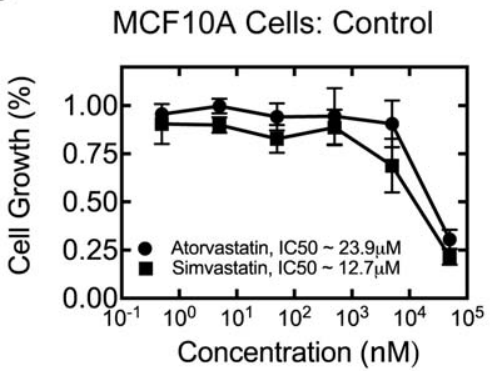

$\mathrm{F}$

UFH-001 Dose Response

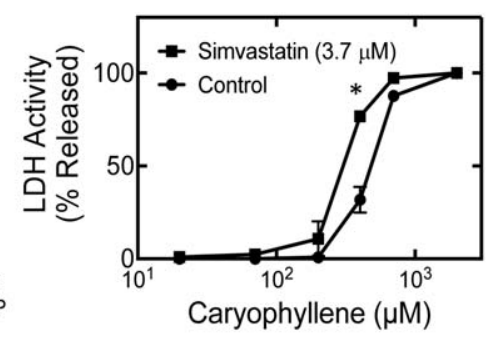

Figure 6. Simvastatin augments the cytotoxic effect of BCP in UFH-001 cells. Panels A-C. UFH-001, T47D, or MCF10 A cells were exposed to specific concentrations of atorvastatin or simvastatin for $48 \mathrm{~h}$. The MTT assay was then used to assess viability/cell growth. $\mathrm{ID}_{50}$ values for atorvastatin and simvastain are displayed in each graph. $* \mathrm{p}=0.028$. Panels D and E. UFH-001 cells were preincubated with atorvastatin (D) or simvastatin (E) for $32 \mathrm{~h}$ at their $\mathrm{IC}_{50}$ values. Then cells were exposed (or not) to hypoxia in the absence or presence of $\mathrm{BCP}(200 \mu \mathrm{M})$ for $16 \mathrm{~h}$. LDH activity was measure in the medium and reported as the $\mu \mathrm{mol} / \mathrm{min} / 10^{6}$ cells (avg \pm SEM). t-test was performed on simvastatin samples. Normoxic samples treated with both simvastatin and BCP vs Control: $* \mathrm{p}=0.046$. Hypoxic samples treated with both simvastatin and BCP vs control: ${ }^{* *} \mathrm{p}=0.008$. Panel F. UFH-001 cells were exposed to simvastatin for $24 \mathrm{~h}$, after which BCP was introduced for an additional $16 \mathrm{~h}$. LDH activity was measured in the medium. Simvastatin induced a 2 -fold shift in the cytotoxicity curve. ${ }^{*} \mathrm{p}=0.016$.

of lipid rafts, lead to the re-organization of these domains followed by activation of specific signaling pathways [43]. In cancer cells, changes in PM lipid composition, among other events, allows the recruitment of selective heat shock proteins like GRP78 (glucose-regulated protein 78 ) by the GRP78 co-factor HJT-1 [44]. GRP78 is normally a resident of the ER where it regulates protein processing and the unfolded protein response [45]. Localization of GRP78 to the PM of cancer cells exhibits therapeutic resistance [46]. While transcription of GRP 78 (HSPA5) is not affected by BCP, we have not measured its translocation to the PM. However, we might expect this if alterations in PM lipid concentration, induced by BCP, serve to recruit GRP78 initiating the resistance response.

Is cholesterol content or redistribution within the PM the key to understanding BCP action? Cholesterol levels in membranes are tightly regulated. Ninety percent of the free cholesterol in cells is associated with the plasma membrane (PM), while smaller pools are found in intracellular membranes like endosomes, secretory vesicles, and caveolae [47, 48]. The ER, where the SREBPs and cholesterolsensing proteins reside, contains only about $1 \%$ of the cell's cholesterol $[47,49]$. This value represents a threshold in that above this concentration (i.e., $5 \mathrm{~mol} \%$ of total ER membrane lipid) cholesterol blocks the activation of SREBP through interaction with its chaperone SCAP [50]. It is only recently that we have begun to appreciate the trafficking of cholesterol between the PM and the ER. Das et al. have shown that there are three cholesterol pools in plasma membranes [51, 52]. In their studies, a mutant form of a cholesterol-binding protein $\left({ }^{125}\right.$ I-labeled Perfringolysin O; ${ }^{125}$ I-PFO) was used to quantify cholesterol content in fibroblast PM. 


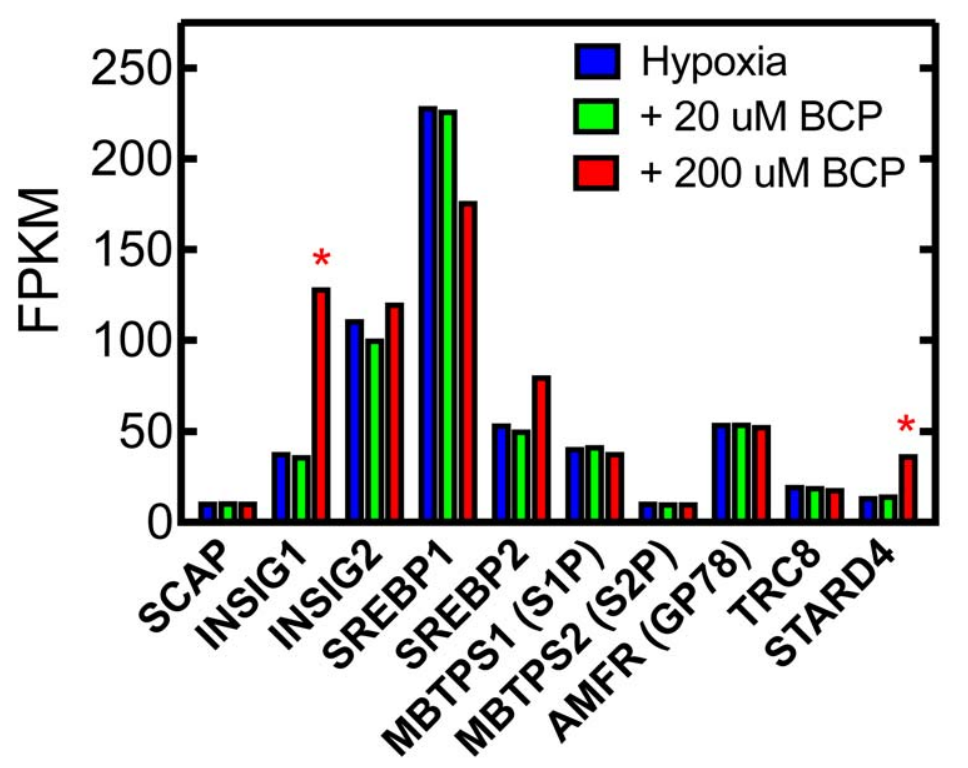

Figure 7. BCP induces transcription of INSIG1 and STARD4. Insig-1 binds to SCAP under cholesterol-replete conditions, which prevents transport of SREBP isoforms to the Golgi. STARD4 is a cholesterol-binding protein that shuttles cholesterol between the plasma membrane and the ER (and other membranes), and is under SREBP transcriptional control. * $\mathrm{q} \leq 0.05$.

These authors discovered that one pool is accessible to ${ }^{125}$ I-PFO binding, which represents $16 \%$ of the PM lipids. This also represents the pool that signals cholesterol excess (or depletion) to the regulatory machinery in the ER. A second pool is associated with a compartment enriched in sphingomyelin. This pool is inaccessible to ${ }^{125}$ I-PFO, unless it is disrupted by treatment with sphingomyelinase. This pool may represent lipid rafts, the higher ordered PM domains that are enriched in sphingomyelin and cholesterol [53]. On average, this pool represents $15 \%$ of PM lipids. A third pool, which was defined as the "essential" pool, accounts for about $12 \%$ of the PM pool and is not accessible, even after sphinomyelinase treatment, to ${ }^{125}$ I-PFO. This pool is required for membrane integrity. When cells are depleted of cholesterol, the PFO-accessible pool becomes depleted. Even thought the other two pools remain intact, there is no trafficking from these pools to the ER. However, when cholesteroldepleted cells are treated with sphingomyelinase, the liberated cholesterol restores the PFO-accessible pool, which is then able to communicate with the ER. It is possible that BCP reduces the concentration of the PFO-accessible pool in the PM leading to cholesterol depletion in the ER. It is also possible that the essential pool is affected which leads to loss of membrane integrity. It could be both, mediated by different concentrations of BCP. While we did not measure PM-specific pools, exposing radioactive cholesterol to $\mathrm{BCP}$-treated cells increases the association of cholesterol relative to controls. As the PM is the major sink for free cholesterol, this infers that the PM pool is depleted by the action of BCP.

Blocking just $1 \%$ of cholesterol transport between the PM and ER leads to activation of cholesterol biosynthesis [54]. Since cholesterol is essentially water insoluble, rapid nonvesicular transport will require carrier proteins. One interesting set of carrier proteins is the steroidogenic acute regulatoryrelated lipid-transfer (START) domain-containing family. The START domain binds cholesterol in a hydrophobic pocket covered by a "lid" that opens to allow exchange with membranes [39, 40]. One subgroup of this family contains only the START domain. Included in this group is STARD4 which increases the formation of cholesteryl esters in the ER [55]. Mesmin et al. have shown that STARD4 can mediate transfer of cholesterol between membranes, and overexpression of STARD4 in cells increases the rate of transfer of sterol to the ER [56]. Because the expression of STARD4 is 
under the control of SREBP-2 [57], this represents a negative feedback loop in which transport of cholesterol to the ER by STARD4 contributes the downregulation of cholesterol biosynthesis. Of note is the 2.5-fold increase in STARD4 transcription in the presence of BCP $(q=0.013)$. Thus, the mechanism of BCP appears complex in that it both activates the cholesterol biosynthetic pathway and at the same time induces a feed back loop to down-regulate that process. This is further evidence that the mechanism of $\mathrm{BCP}$ action is through cholesterol depletion because the same regulatory steps are affected by both $\mathrm{BCP}$ and cholesterol.

In contrast to the studies described herein, other investigators have reported hypolipidemic effects of BCP [58-61]. These observations were detected, in vivo, under both hyperlipidemic and hypercholesterolemic conditions. In both models, the concentration of $\mathrm{BCP}$ that was achieved in vivo was about $130 \mu \mathrm{M}$. At this circulating concentration, $\mathrm{BCP}$ was able to reduce circulating cholesterol and LDL cholesterol in hyperlipidemic but not normal animals. The target of this action is inhibition of HMGCR activity. In addition, BCP $(1.5 \mathrm{~g} / \mathrm{kg}$ of diet, or $0.15 \%)$ inhibits tumor growth and lung metastasis of melanoma cells in a dietinduced obesity mouse model [62]. In this model, BCP decreased lipid content in macrophage and adipocytes associated with the lung, and reduced the concentration of growth factors and cytokines associated with tumor tissue. They also showed that BCP suppressed VEGF expression, which is likely responsible for the observed reduction in tumor angiogenesis. Thus the action of BCP may depend on its concentration, the target tissue, and metabolic state of that tissue.

While simvastatin sensitized UFH-001 cells to the cytotoxic effects of BCP, this shift was only about 2 fold. However, this does open the possibility for combinatorial therapy if we could target cancer cells specifically. Preferential expression of GRP78 to the cell surface of tumor cells could serve that role. In fact, synthetic peptides mimicking GRP78 binding motifs fused to cell death-inducing peptides or cytotoxic drugs are able to promote apoptosis in cancer cells in vitro, including breast cancer cells [63]. Another possibility is to change the structure of $\mathrm{BCP}$ to make it a better cytotoxic reagent. Terpenes are not the best starting material for drug development. However, studies from the Gertsch lab [64] showed that removing the conformational constraints induced by the medium-sized ring and by introducing functional groups at the sesquiterpene hydrocarbon 1 (see reference 16 for carbon labeling), this new scaffold created a structure that not only binds to the $\mathrm{CB}_{2}$ receptor, but reversibly inhibits fatty acid amide hydrolase, the major endocannabinoid degrading enzyme. This might serve to prolong the effects of $\mathrm{BCP}$, and make possible its use at lower concentrations.

\section{CONCLUSION}

In conclusion, we have shown that $\mathrm{BCP}$ induces a striking transcriptional upregulation of the cholesterol biosynthetic pathway, possibly providing cytoprotection for membrane structures and/or inducing drug resistance. However, blocking this path increases BCP-induced induced cytotoxicity suggesting a strategy for combinatorial therapy. In future studies, we will examine changes in membrane lipid and protein composition, the association with GRP78 translocation, and metabolic flux in lipid biosynthetic pathways in BCP-treated cells.

\section{ACKNOWLEDGEMENTS}

The authors would like to recognize the exceptional cell culture skills of Xiao Wei Gu.

\section{FUNDING}

This research was financed by the National Institutes of Health, project CA165284 (SCF) and minority supplement CA165284-03S1 (MYM). Funding also came from the Ocala Royal Dames Research Foundation (CJF and SCF). Part of this work was performed with assistance of the University of Louisville Genomics Facility and Bioinformatics Core, which was supported by NIH/NIGMS Phase III COBRE P30 GM106396, NIH/NIGMS KY-INBRE P20GM103436, the James Graham Brown Foundation, and user fees. Funding for RNA sequencing was provided under the aegis of the NIH/NIGMS Phase III COBRE P30 GM106396 by the Kentucky Biomedical Research Infrastructure Network (KBRIN) Next Generation Sequencing (NGS) project KBRIN0093 
(CJF). The content is solely the responsibility of the authors and does not necessarily represent the official views of the National Institutes of Health.

\section{CONFLICT OF INTEREST STATEMENT}

The authors declare that they have no conflicts of interest with the contents of this article.

\section{SUPPLEMENTARY MATERIAL}

A
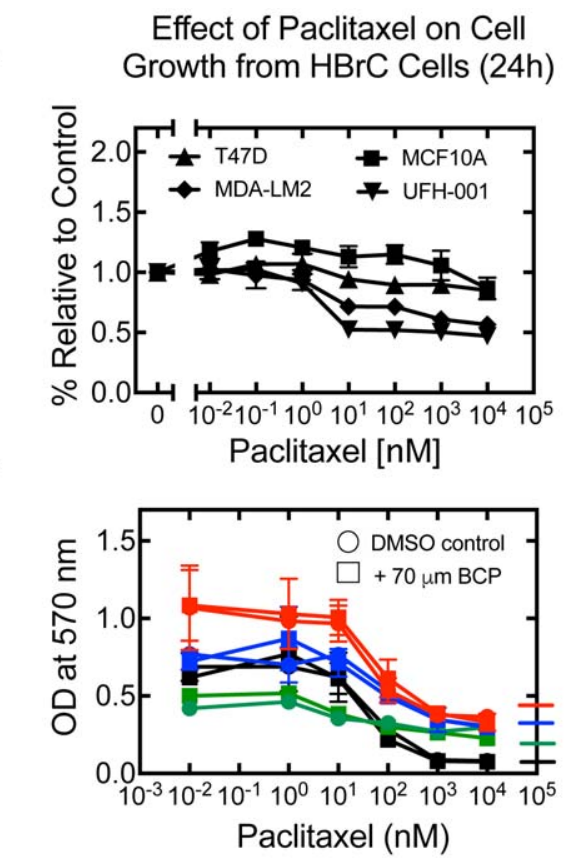

B

Effect of Paclitaxel on Cell Growth from HBrC Cells (48h)
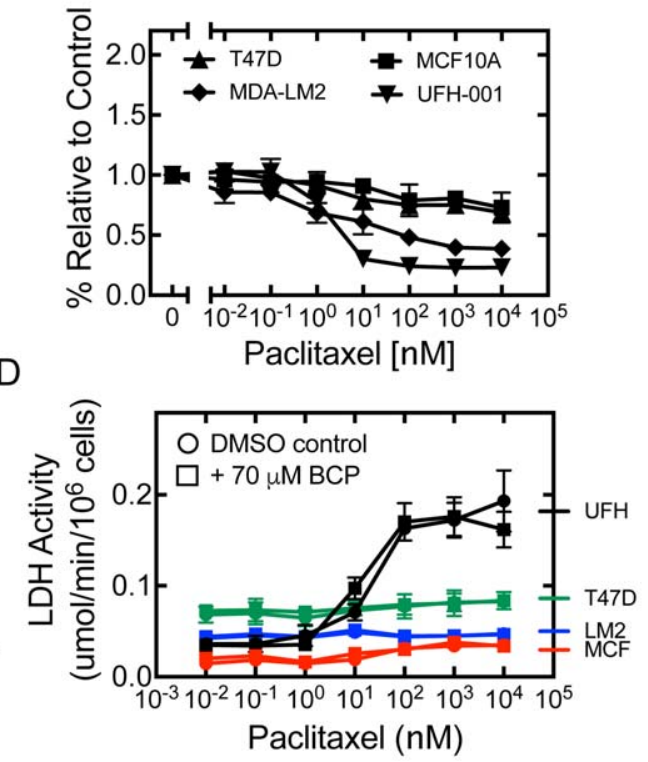

Supplementary Figure 1. Paclitaxel reduces growth of aggressive breast cells. Panels $\mathbf{A}$ and B. UFH-001, MDA-MB-231 LM2, T47D, or MCF10 A cells were exposed to specific concentrations of Paclitaxel for $24 \mathrm{~h}$ (Panel A) or $48 \mathrm{~h}$ (Panel B). The MTT assay was then used to assess viability/cell growth. Data are reported as percent of control: avg \pm S.E.M., $n=3$. Panel C. $L D H$ activity was measured in the medium of cells treated with specific concentrations of Paclitaxel for $32 \mathrm{~h}$ followed by exposure to $70 \mu \mathrm{M} \mathrm{BCP}$ or vehicle for $16 \mathrm{~h}$. Data are reported as the avg \pm S.E.M., $\mathrm{n}=3$. Panel D. Under the same conditions as in Panel C, the MTT assay was performed for $48 \mathrm{~h}$ to assess viability/cell growth. Data are presented at $\mathrm{OD}$ at 570: $\operatorname{avg} \pm$ S.E.M., $\mathrm{n}=3$.

\section{Effect of $\beta$-Caryophyllene on LDH Release from UFH-001 Cells}

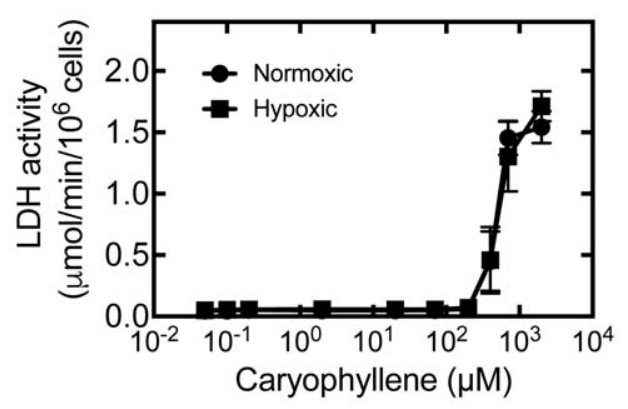

Supplementary Figure 2. Cytotoxicity of BCP is not affected by hypoxia. Cells were exposed to normoxic or hypoxic condition in the presence of increasing concentrations of BCP. LDH release was measured after $16 \mathrm{~h}$. Data shown represent the average of at least 3 biological replicates \pm S.E.M. 


\section{REFERENCES}

1. World Cancer Research Fund International, 2012, Breast Cancer Statistics.

2. Jones, S. 2008, Clin. Breast Cancer, 8, 224233.

3. Peddi, P. F., Ellis, M. J. and Ma, C. 2012, Internat. J. Breast Canc., 2012, 7.

4. Schneider, B. P., Winer, E. P., Foulkes, W. D., Garber, J., Perou, J. M., Richardson, A., Sledge, G. W. and Carey, L. A. 2008, Clin. Cancer Res., 14, 8010-8018.

5. Farmer, E. E. 2014, Leaf Defence, OUP Oxford.

6. Bayala, B., Bassole, I. H., Scifo, R., Gnoula, C., Morel, L., Lobaccaro, J. M. and Simpore, J. 2014, Am. J. Cancer Res., 4, 591-607.

7. Gershenzon, J. and Dudareva, N. 2007, Nature Chem. Biol., 3, 408-414.

8. Hunter, W. N. 2007, J. Biol. Chem., 282, 21573-21577.

9. Frost, C. J., Appel, H. M., Carlson, J. E., de Moraes, C. M., Mescher, M. C. and Schultz, J. C. 2007, Ecol. Lett., 10, 490-498.

10. Frost, C. J., Mescher, M. C., Dervinis, C., Davis, J. M., Carlson, J. E. and de Moraes, C. M. 2008, New Phytologist, 180, 722-734.

11. Schiff, P. B. and Horwitz, S. B. 1980, Proc. Natl. Acad. Sci. USA, 77, 1561-1565.

12. Heinig, U., Scholz, S. and Jennewein, S. 2013, Fungal Diversity, 60, 161-170.

13. Perez, E. A. 1998, Oncologist, 3, 373-389.

14. Fidyt, K., Fiedorowicz, A., Strzadala, L. and Szumny, A. 2016, Cancer Med., 5, 3007-3017.

15. Dahham, S. S., Tabana, Y. M., Iqbal, M. A., Ahamed, M. B., Ezzat, M. O., Majid, A. S. and Majid, A. M. 2015, Molecules, 20, 11808-11829.

16. Gertsch, J., Leonti, M., Raduner, S., Racz, I., Chen, J. Z., Xie, X. Q., Altmann, K. H., Karsak, M. and Zimmer, A. 2008, Proc. Natl. Acad. Sci. USA, 105, 9099-9104.

17. Bayala, B., Bassole, I. H., Gnoula, C., Nebie, R., Yonli, A., Morel, L., Figueredo, G., Nikiema, J. B., Lobaccaro, J. M. and Simpore, J. 2014, PLoS One, 9, e92122.

18. Amiel, E., Ofir, R., Dudai, N., Soloway, E., Rabinsky, T. and Rachmilevitch, S. 2012, Evid. Based Complement. Alternat. Med., 2012, 872394.
19. Legault, J. and Pichette, A. 2007, J. Phar. Pharmacol., 59, 1643-1647.

20. Huang, M., Sanchez-Moreiras, A. M., Abel, C., Sohrabi, R., Lee, S., Gershenzon, J. and Tholl, D. 2012, New. Phytol., 193, $997-$ 1008.

21. Tambe, Y. Tsujiuchi, H., Honda, G., Ikeshiro, Y. and Tanaka, S. 1996, Planta Med., 62, 469-470.

22. Ghelardini, C., Galeotti, N., Di Cesare, M., Mazzanti, G. and Bartolini, A. 2001, Farmaco, 56, 387-389.

23. Di Sotto, A., Evandri, M. G. and Mazzanti, G. 2008, Mutat. Res., 653, 130-133.

24. Sarpietro, M. G., Di Sotto, A., Accollla, M. L. and Castelli, F. 2015 Thermochimica Acta, 600, 28-34.

25. Sikkema, J., de Bont, J. A. and Poolman, B. 1994, J. Biol. Chem., 269, 8022-8028.

26. Holthuis, J. C. and Menon, A. K. 2014, Nature, 510, 48-57.

27. Brown, M. S., Radhakrishnan, A. and Goldstein, J. L. 2018, Annu. Rev. Biochem., 87, 783-807.

28. Chen, Z., Ai, L., Mboge, M. Y., McKenna, R., Frost, C. J., Heldermon, C. D. and Frost, S. C. 2018, Cancer Biol. Ther., 19, 598-608.

29. Edgar, R., Domrachev, M. and Lash, A. E. 2002, Nucleic Acids Res., 30, 207-210.

30. Markwell, M. A. K., Haas, S. M., Lieber, L. L. and Tolbert, N. E. 1978, Anal. Biochem., 87, 206-210.

31. Laemmli, U. K. 1970, Nature, 227, 680-685.

32. Li, Y., Tu, C., Wang, H., Silverman, D. N. and Frost, S. C. 2011, J. Biol. Chem., 286, 15789-15796.

33. Chen, Z., Ai, L., Mboge, M. Y., Tu, C., McKenna, R., Brown, K. D., Heldermon, C. D. and Frost, S. C. 2018, PLoS One, 13, e0199476.

34. Keating, P., Cambrosio, A., Nelson, N. C., Mogoutov, A. and Cointet, J. P. 2013, Front. Pharmacol., 4, 58.

35. Li, Y., Wang, H., Oosterwijk, E., Tu, C., Shiverick, K. T., Silverman, D. N. and Frost, S. C. 2009, Cancer Invest., 27, 613-623.

36. Horton, J. D., Goldstein, J. L. and Brown, M. S. 2002, Cold Spring Harb. Symp. Quant. Biol., 67, 491-498. 
37. Lanczky, A., Nagy, A., Bottai, G., Munkacsy, G., Szabo, A., Santarpia, L. and Gyorffy, B. 2016, Breast Cancer Res. Treat., 160, 439-446.

38. Goldstein, J. L. and Brown, M. S. 1990, Nature, 343, 425-430.

39. Soccio, R. E. and Breslow, J. L. 2003, J. Biol. Chem., 278, 22183-22186.

40. Alpy, F. and Tomasetto, C. 2005, J. Cell Sci., 118, 2791-2801.

41. Brown, M. S. and Goldstein, J. L. 1997, Cell, 89, 331-340.

42. Vigh, L., Nakamoto, H., Landry, J., GomezMunoz, A., Harwood, J. L. and Horvath, I. 2007, Ann. N. Y. Acad. Sci., 1113, 40-51.

43. Nagy, E., Balogi, Z., Gombos, I., Akerfelt, M., Bjorkbom, A., Balogh, G., Torok, Z., Maslyanko, A., Fiszer-Kierzkowska, A., Lisowska, K., Slotte, P. J., Sistonen, L., Horvath, I. and Vigh, L. 2007, Proc. Natl. Acad. Sci. USA, 104, 7945-7950.

44. Birukova, A. A., Singleton, P. A., Gawlak, G., Tian, X., Mirzapoiazova, T., Mambetsariev, B., Dubrovskyi, O., Oskolkova, O. V., Bochkov, V. N. and Birukov, K. G. 2014, Mol. Biol. Cell, 25, 2006-2016.

45. Lee, A. S. 2014, Nat. Rev. Cancer, 14, 263276.

46. Zhang, Y., Tseng, C. C., Tsai, Y. L., Fu, X., Schiff, R. and Lee, A. S. 2013, PLoS One, 8, e80071.

47. Lange, Y. 1991, J. Lipid Res., 32, 329-339.

48. Lange, Y., Swaisgood, M. H., Ramos, B. V. and Steck, T. L. 1989, J. Biol. Chem., 264, 3786-3793.

49. Sokolov, A. and Radhakrishnan, A. 2010, J. Biol. Chem., 285, 29480-29490.

50. Radhakrishnan, A., Goldstein, J. L., McDonald, J. G. and Brown, M. S. 2008, Cell Metab., 8, 512-521.

51. Das, A., Brown, M. S., Anderson, D. D., Goldstein, J. L. and Radhakrishnan, A. 2014, eLife, 3, e02882.

52. Das, A., Goldstein, J. L., Anderson, D. D., Brown, M. S. and Radhakrishnan, A. 2013,
Proc. Natl. Acad. Sci. USA, 110, 1058010585.

53. Simons, K. and Sampaio, J. L. 2011, Cold Spring Harb. Perspect. Biol., 3, a004697.

54. Infante, R. E. and Radhakrishnan, A. 2017, eLife, 6, e25466.

55. Rodriguez-Agudo, D., Ren, S., Wong, E., Marques, D., Redford, K., Gil, G., Hylemon, P. and Pandak, W. M. 2008, J. Lipid Res., 49, 1409-1419.

56. Mesmin, B., Pipalia, N. H., Lund, F. W., Ramlall, T. F., Sokolov, A., Eliezer, D. and Maxfield, F. R. 2011, Mol. Biol. Cell, 22, 4004-4015.

57. Soccio, R. E., Adams, R. M., Maxwell, K. N. and Breslow, J. L. 2005, J. Biol. Chem., 280, 19410-19418.

58. Tzeng, T. F., Lu, H. J., Liou, S. S., Chang, C. J. and Liu, I. M. 2014, Food. Chem. Toxicol., 69, 132-139.

59. Baldissera, M. D., Souza, C. F., Grando, T. H., Doleski, P. H., Boligon, A. A., Stefani, L. M. and Monteiro, S. G. 2017, NaunynSchmiedeberg's Arch. Pharmacol., 390, 215223.

60. Baldissera, M. D., Souza, C. F., Doleski, P. H., Leal, D. B. R., Stefani, L. M., Boligon, A. A. and Monteiro, S. G. 2017, Mol. Cell. Biochem., 434, 127-134.

61. Harb, A. A., Bustanji, Y. K. and Abdalla, S. S. 2018, J. Clin. Biochem. Nutr., 62, 230237.

62. Jung, J. I., Kim, E. J., Kwon, G. T., Jung, Y. J., Park, T., Kim, Y., Yu, R., Choi, M. S., Chun, H. S., Kwon, S. H., Her, S., Lee, K. W. and Park, J. H. 2015, Carcinogenesis, 36, 1028-1039.

63. Arap, M. A., Lahdenranta, J., Mintz, P. J., Hajitou, A., Sarkis, A. S., Arap, W. and Pasqualini, R. 2004, Cancer Cell, 6, 275 284.

64. Chicca, A., Caprioglio, D., Minassi, A., Petrucci, V., Appendino, G., TaglialatelaScafati, O. and Gertsch, J. 2014, ACS Chem. Biol., 9, 1499-1507. 